\title{
O SER CRIANÇA: PERCEPÇÃO DE ALUNAS DE UM CURSO DE GRADUAÇÃO EM ENFERMAGEM
}

\author{
Maria Aparecida Munhoz Gaíva* \\ Mara Regina Ribeiro Souza Paião**
}

GAÍVA, M.A.M.; PAIÃO, M.R.R.S. O ser criança: percepção de alunas de um curso de graduação em enfermagem.

Rev.latino-am.enfermagem, Ribeirão Preto, v. 7, n. 1, p. 75-83, janeiro 1999.

As autoras tiveram como objetivo conhecer a percepção sobre criança, de alunas do $4^{\circ}$ semestre de graduação em enfermagem de uma Universidade Pública Brasileira. Para tanto solicitaram às alunas que escrevessem acerca de sua percepção sobre crianças, no primeiro e último dias de atividades acadêmicas na disciplina de Enfermagem Pediátrica. Utilizando a abordagem qualitativa, analisaram os relatos, identificando os seguintes núcleos temáticos: "ser pequeno, frágil e inocente", "ser humano cidadão", "ser humano em fase de desenvolvimento", "ser que se diverte", "O ambiente e a formação da criança" e a "interação da criança com o adulto". Os resultados mostram que, inicialmente, as alunas percebiam a criança como ser frágil, imaturo e despreparado para enfrentar a vida, necessitando da proteção do adulto. Ao final da disciplina passam a ver a criança como um ser em fase de desenvolvimento, como cidadão e com os mesmos direitos do adulto.

UNITERMOS: percepção de criança, alunas de enfermagem

\section{1 - INTRODUÇÃO}

Atualmente, a despeito de todos os avanços científicos e tecnológicos obtidos, a criança é desconhecida pelos profissionais de saúde, tanto no que diz respeito aos agravos ao seu desenvolvimento, como principalmente em relação ao papel social que tem a desempenhar na nossa organização cultural.

Há algum tempo, na prática como professoras de Enfermagem Pediátrica, do Curso de Graduação em Enfermagem da Universidade Federal de Mato Grosso, tem-nos preocupado a percepção sobre a criança veiculada no processo ensino-aprendizagem, como também as percepções, crenças e valores trazidos pelas alunas*** de seu meio sócio-cultural.

A percepção sobre o papel cultural da criança é fundamental para enfermeiros que pretendam atuar em pediatria, uma vez que ela demarca a atuação desses profissionais junto às crianças.

De acordo com ÂNGELO (s/d), as práticas em relação à criança são sempre orientadas por uma concepção de criança, mesmo que o profissional não a perceba.
Verificamos no dia-a-dia que a percepção das alunas relacionada às crianças é a de um ser humano fragilizado e pequeno, que requer habilidades específicas de quem se propõe a lhes prestar cuidados.

As alunas freqüentemente verbalizam sobre o medo de "quebrar" a criança e de lidar com ela, fatos estes que nos permitem perceber a ansiedade que a atividade com crianças lhes desperta.

Em razão desta postura, procuramos modificar a iniciação das alunas no contato com o cliente pediátrico, começando pela atenção junto à criança clinicamente saudável, em serviços tais como creches e escolas e, posteriormente, passando a introduzir as alunas junto à serviços mais complexos de atendimento à criança, tais como Centros de Saúde, Hospitais e Unidades de Terapia Intensiva, de maneira a tornar mais produtiva e menos traumática a passagem pela disciplina.

Percebemos, entretanto, que essas modificações não foram suficientes, uma vez que a percepção incorporada ao longo de sua vida, não é alterada em curtos espaços de tempo, como os que dispomos na disciplina de Enfermagem Pediátrica.

Acreditamos ser necessário conhecer, sob o ponto

\footnotetext{
* Professora assistente do departamento de enfermagem materno-infantil da Faculdade de Enfermagem e Nutrição da Universidade Federal de Mato Grosso

** Professora assistente do departamento de enfermagem materno-infantil da Faculdade de Enfermagem e Nutrição da Universidade Federal de Mato Grosso

*** Utilizaremos o gênero feminino por ser predominante em nossa área de atuação
} 
de vista das alunas, as percepções a respeito de crianças, para podermos adotar estratégias de ensino-aprendizagem adequadas. Antes contudo, é necessário conhecer através da história, a trajetória da criança no contexto da família e da sociedade.

\section{2 - BREVE NARRATIVA HISTÓRICA ACERCA DA CRIANÇA}

Para a Organização Mundial da Saúde a infância é o período da vida humana compreendido do nascimento até os 10 anos de idade, e a pessoa nessa fase recebe a denominação de criança. Mas ao buscarmos no dicionário a definição da palavra criança encontramos que criança é um "ser humano de pouca idade, menino ou menina; párvulo. Pessoa ingênua, infantil: não desconfia de nada, é uma criança" (FERREIRA, 1986).

No decorrer da história, a criança tem ocupado diferentes posições, dependendo do valor que a sociedade lhe dava. O historiador Philippe Ariés, em sua obra "História Social da criança e da família", nos traça uma trajetória de como a criança vem sendo tratada ao longo dos séculos. Ressalta, por exemplo, que a infância sempre esteve ligada à idéia de dependência, assim a criança, no decorrer da história, vem sendo tratada como alguém com perspectiva de "vir- a- ser", mas que ainda não é (ARIÉS, 1981).

A infância permaneceu no anonimato até fins do século XII. Os pintores e miniaturistas dessa época apresentam a criança como adultos de tamanho reduzido, demonstrando a posição que ocupava na sociedade em geral.

No entanto, a indiferença não ocorria apenas no que diz respeito às imagens, mas as roupas usadas pela criança daquela época comprovavam bem quanto a infância era pouco particularizada na vida real. Assim que o recém-nascido deixava os cueiros, passava, então, a ser vestido como os adultos.

A falta de singularidade que era conferida à criança não se restringia apenas ao plano representativo. O pai tinha sobre o filho o direito de vida e de morte, direito de castigá-lo, de mandar flagelá-lo, de condená-lo à prisão, de excluí-lo enfim, da família (BADINTER, 1985).

Até o século XVII a infância era ignorada e considerada por todos um período de transição. A partir do século XVII, ela passa a ser reconhecida como uma etapa distinta e com características próprias do desenvolvimento humano. A criança sai do anonimato e passa a ter um mundo próprio separado do mundo do adulto (ARIÉS, 1981).

Pode-se constatar pela literatura que a ascensão da infância enquanto conceito e preocupação específica é contemporâneo ao progressivo declínio do poder do pai na família e na sociedade. Até meados do século XIX, o pai ocupava o lugar de rei sobre os filhos e a mulher. $\mathrm{O}$ pai possuía poderes duplos, ele dominava na esfera pública e na doméstica; pois cabiam a ele as decisões fundamentais quanto ao destino dos filhos como, onde estudar, com quem se casar.

Paralelamente, ocorre uma progressiva valorização do lugar ocupado pela criança e o filho no decorrer do século XIX, vai ocupar cada vez mais o centro da família. Ele passa a ser objeto de investimentos econômico, educacional e afetivo (BADINTER, 1985).

Nesse século a infância torna-se o centro das atenções e passa a ser considerada a idade fundadora da vida, passando a ser matéria de estudos e observações. Desta forma, aos poucos a criança vai assumindo identidade, voz e estatuto legal.

Todas essas alterações sócio-culturais no modo de perceber e tratar a infância, acabaram por conduzir, mesmo que gradativamente, a algumas melhorias. Fundamentada na necessidade de vê-la como um ser singular, surgiram, então, a Pediatria, como especialidade da medicina; a criação de vestimentas próprias à infância, brinquedos infantis, dentre outros. Em 1959, foi proclamada a Declaração dos Direitos da Criança, e mais recentemente, como fruto da Constituição Brasileira de 1988, foi aprovado, sob forma de lei, o Estatuto da Criança e do Adolescente em 1990**** (BRASIL, 1991).

Comparando o ser criança hoje, às crianças nascidas antes do século XIX, percebemos que não obstante as mudanças ocorridas, ainda não conseguimos respeitá-las como co-autoras do universo. Elas continuam em nossa realidade, escravas dos desejos e ansiedades dos adultos, que não conseguem perceber nelas a capacidade de pensar, querer e de sentir. A tendência é vê-las como seres dependentes e que necessitam ser protegidas.

Para DALLARI \& KORCZAC (1986, p. 53) “A preocupação com a proteção da criança não deve servir de pretexto para anulação de sua criatividade, assim como a indiferença pela criança não pode ser confundida com o respeito por sua liberdade. É preciso que se conjuguem ambos, a proteção e o respeito, para que a criança possa exercer em toda plenitude, o seu direto de viver. E viver é participar da vida, é acrescentar alguma coisa à criação, 
é imprimir sua marca no mundo criado.

Desse modo, o exercício do direito ‘a vida deve ser constante prática do pensar, do falar e do agir, da expressão livre do diálogo"(....).

De acordo com a história, a proteção da sociedade para com a criança, pode ser demarcada em dois períodos distintos: o primeiro, compreendido entre os séculos XII e o século XVI quando quase nada se fazia por ela, uma vez que reduzida importância the era atribuída; e outro, a partir do século XVII, em que quase tudo se quer realizar por ela. Esses dois momentos trazem em comum, a impossibilidade a que a criança foi submetida de assumir o seu espaço, uma vez que por omissão ou superproteção, o adulto a impede de mostrar-se um ser em toda a sua plenitude ( SANTANA, 1995).

Nos dias atuais, já às portas do terceiro milênio, observa-se que convivem, de certo modo harmonicamente, diferentes formas de perceber e tratar as crianças, persistindo a omissão de alguns, a superproteção por parte de outros e o respeito ao ser criança por poucos, que lhe permitem tomar parte na história, desempenhando seu papel social.

A partir do reconhecimento da criança como indivíduo único, portador de necessidades e capacidades próprias, ocorrem também modificações nos objetivos da assistência à criança, que deixa de focalizar a doença, passando a enfatizar a promoção à saúde.

Detendo-nos agora um pouco mais acerca da influência de nossa visão de criança na assistência à saúde, percebemos ser evidente que não é suficiente a aquisição de conhecimentos técnico-científicos sobre crescimento e desenvolvimento, mas também é necessário compreender como a cultura contribui para o desenvolvimento das relações e atitudes sociais relativas às práticas de saúde junto à criança.

Para WHALEY \& WONG (1989), a cultura em que as crianças nascem determina não só os papéis familiares, mas também grande parte das atitudes e comportamentos que adotam durante sua vida, pois as crianças aprendem a se adaptar a um tipo de comportamento concordante com os padrões próprios de seu grupo social.

Identificar as questões culturais torna-se fundamental em nossa prática diária, para que possamos reconhecer que determinados comportamentos da criança podem ser resultantes de um grupo cultural específico, contribuindo desta forma, no relacionamento e no respeito às diferenças culturais da criança.

$\mathrm{O}$ respeito à criança por parte dos profissionais da saúde inclui dentre outros, a permissão para que ela participe ativamente do planejamento do processo assistencial, recebendo informações, sendo consultada, fazendo as escolhas possíveis, ou seja, sendo tratada como sujeito de direitos.
Até a publicação do Estatuto da Criança e do Adolescente, em julho de 1990 (BRASIL, 1991), é possível verificar a continuidade da negação formal e substancial da criança e do adolescente como sujeitos de direitos.

Esta negação formal dos direitos fundamentais, incluindo explicitamente as mais elementares garantias constitucionais, é causa e conseqüência de uma cultura da incapacidade social, onde a incapacidade jurídica se assenta. Essa cultura, baseando-se na exclusão social, reforça e legitima a situação introduzindo uma dicotomia perversa no mundo da infância.

De tudo isso, surge a profunda necessidade de resgatar a infância, no avesso das técnicas de dominação e submissão, que se manifestam em negação da condição de sujeito de direitos, construindo-se uma estratégia de formação de cidadania para a infância.

Para COVRE-MANZINI (1995, p. 11) "Cidadania é o próprio direito à vida no sentido pleno." Ela tem origem com o surgimento da vida nas cidades, à capacidade de os homens exercerem direitos e deveres de cidadãos.

Em relação a infância, o Estatuto da Criança e do Adolescente (BRASIL, 1991) preconiza que crianças e adolescentes são sujeitos de direitos, portanto gozam de todos os direitos fundamentais inerentes à pessoa humana.

Sem a pretensão de esgotar a temática, a nossa proposta tem a intenção de compreender melhor a criança sob a ótica de alunas de graduação de enfermagem, futuras profissionais que amanhã estarão prestando assistência à criança. Dessa forma, passamos a buscar junto à alunas do quarto semestre de um Curso de Graduação em Enfermagem, respostas para a seguinte indagação:

- Qual a percepção de alunas do quarto semestre do Curso de Graduação em Enfermagem em relação à criança?

A partir do exposto, estabelecemos como objetivos:

Compreender e descrever a percepção sobre crianças, de alunas do quarto semestre do Curso de Graduação em Enfermagem.

Comparar a percepção sobre crianças, de alunas do quarto semestre do Curso de Graduação em Enfermagem, no início e final da disciplina de Enfermagem Pediátrica.

\section{3 - METODOLOGIA}

Trata-se de uma pesquisa com abordagem qualitativo-descritiva que nos permitiu entender a natureza de um fenômeno social, levando os pesquisadores a 
detectarem os significados que as pessoas dão aos fenômenos (TRIVIÑOS, 1987). Desta forma, este tipo de abordagem mostrou-se adequada para o estudo em questão. $\mathrm{O}$ estudo foi realizado com alunas do quarto semestre do Curso de Graduação em Enfermagem de uma Universidade Pública.

Os dados foram coletados no periodo entre março e maio de 1995. Solicitamos às alunas que escrevessem sobre a percepção em relação à criança, no inicio e final da disciplina de Enfermagem Pediátrica, sendo estes relatos tratados de primeiro momento e os do final como segundo momento.

As alunas tiveram liberdade de participar ou não da atividade, e desta forma obtivemos 16 (dezesseis) relatos no primeiro momento, e 15 (quinze) no segundo.

Os relatos das alunas foram analisados com base nas indicações de LUDKE \& ANDRÉ (1986). Após a leitura de todos os relatos, procuramos determinar, nos textos transcritos, significados que fossem comuns a todos os relatos. Uma vez identificados esses significados, passamos para a fase de classificação das informações. Esta classificação consistiu numa exploração mais profunda do material.

Tomando por base os objetivos e a questão norteadora do estudo, organizamos os núcleos temáticos. Esses núcleos temáticos não foram selecionados a priori, mas emergiram do relato dos sujeitos da pesquisa.

Após definir os núcleos temáticos, passamos à discussão e interpretação das informações. Os núcleos temáticos serão apresentados a seguir com as seguintes denominações:

"Ser pequeno, frágil e inocente" (Primeiro e segundo momentos); "Ser humano cidadão" (Segundo momento); "Ser que se diverte" (Primeiro e segundo momentos); "O ambiente e a formação da criança" (Primeiro e segundo momentos); "Ser em fase de desenvolvimento" (Segundo momento);“ A Interação da criança com o adulto" (Primeiro e segundo momentos).

\section{4 - AS PERCEPÇÕES SOBRE CRIANÇA}

Ao compreendermos as percepções manifestadas pelas alunas de enfermagem teremos subsídios para a visualização das possibilidades de mudanças na prática pedagógica da disciplina de Enfermagem Pediátrica.

Acreditamos que nossa interação com crianças, quer seja no âmbito profissional ou familiar, é alicerçada nas percepções que temos sobre elas, percepções estas construídas social e culturalmente ao longo de um processo histórico, como já foi abordado na introdução.

\section{1. "Ser pequeno, frágil e inocente"}

A criança é percebida pelas alunas, como um ser imaturo, ou seja, que não possui as mesmas capacidades de um adulto, estando em decorrência disto, despreparada para a vida. Neste sentido, a criança é entendida como um ser pequeno e fragilizado, necessitando portanto, da proteção dos adultos.

A criança pode ser caracterizada por certas particularidades, dependendo do estágio de seu crescimento e desenvolvimento; são justamente essas características que as diferenciam do adulto, porém ela não deixa de expressar um ser humano completo e que vai desenvolver seu potencial à medida em que existam condições facilitadoras para tal. Para MACHADO (1985) a criança tem necessidades afetivas básicas para o seu desenvolvimento, e uma delas é a de proteção; esta se contrapõe à necessidade de independência, ou seja, quanto mais nova a criança, maior sua necessidade de proteção e menor a de independência.

"A criança é um ser humano pequeno, frágil, e devido à sua imaturidade, são mais despreparados para a vida". (Primeiro momento, Relato 14)

"...aquele serzinho que quando nasce é frágil..." (Primeiro momento, Relato 02)

$\mathrm{Na}$ idade média o conceito de infância estava ligado à idéia de dependência, e a criança só saía desse período ao deixar de ser dependente do adulto (ARIÉS, 1981).

Ao nosso ver a questão da fragilidade da criança também pode estar associada às altas taxas de mortalidade vigentes até o século XVIII, gerando um sentimento de indiferença em relação à infância, já que a possibilidade de perda era muito elevada.

Outra nuance identificada é a da criança como "Ser inocente e puro, desprovido de qualquer maldade". Estes dados reforçam a compreensão de criança como ser diferenciado do adulto, tanto no aspecto relativo às capacidades, como às características emocionais/ afetivas.

"Ser criança é ter inocência, é não ter maldade no coração." (Primeiro momento, Relato 04)

Outra característica evidenciada foi a da criança como ser autêntico, que se mostra ao mundo sem máscaras e/ou fingimentos. Além disto, algumas características especiais são apresentadas: a criança como ser humano bom, livre de sentimentos ruins em relação às outras pessoas, e que pode ser influenciada na convivência com os demais.

"A criança não guarda ódio em seu coração". (Primeiro momento, Relato 10) “...mas também são extremamente 
influenciáveis..." (Primeiro momento,

Relato 13)

No segundo momento dos relatos, persiste a visão de criança como ser inocente, puro e fragilizado, entretanto não foi possível evidenciar a nuance de desproteção, despreparo e imaturidade para a vida. A criança é apontada também, como ser carinhoso e carente.

"Toda criança é frágil, sensível e carente." (Segundo momento, Relato 14)

A percepção de que a criança é um presente de Deus foi apontada somente no primeiro momento de relatos.

"Criança para mim é uma coisa linda, um presente de Deus". (Primeiro momento, Relato 10)

A associação da criança a Deus pode ser vista na literatura desde o século XVI e XVII, quando a consideravam como um ser inocente, semelhante aos anjos, criaturas a quem Cristo amou (ARIÉS, 1981).

Para as alunas as crianças "Presente de Deus" são as que preenchem as expectativas do adulto para seres que se encontram nesta fase da vida - a infância. São inocentes, sinceras, bem cuidadas, alegres e bonitas. Constituem, na verdade, o protótipo da criança perfeita, presente de Deus para os adultos, e ainda, aquela criança que têm um lar.

\subsection{Ser humano cidadão}

Da interpretação do segundo momento dos relatos, chegamos à compreensão da criança como ser humano, essencialmente diferente daquele apresentado no tópico anterior. A criança é situada como ser que possui um espaço na sociedade, e que deve ser respeitado como tal. São seres que têm direitos especiais.

"....é um ser humano, portanto digna de respeito e atenção, tem direito a falar e ser ouvida e ocupar o espaço que a ela é destinado". (Segundo momento, Relato 02)

Neste sentido, a criança desfruta do direito de participar ativamente na construção de sua própria história, direito este que necessita ser respeitado na família, através de atividades elementares como: saber ouvir, permitir que a criança pense, sinta, expresse seus sentimentos, participe ativamente da vida familiar, sobretudo possibilitando que desenvolva plenamente suas potencialidades, em cada fase de desenvolvimento que se encontre.

Face ao exposto, a criança estará apta a fazer escolhas e tomar decisões, de acordo com o momento de sua vida, tendo claro o papel dos responsáveis neste processo. Sendo a criança, um cidadão no sentido literal, não podemos retirar as responsabilidades civis e criminais dos responsáveis e da própria sociedade no processo de formação desse cidadão.

Na perspectiva da cidadania, a criança goza de plenos direitos, assim como o adulto. Entretanto, há necessidade de considerá-la em suas especificidades, o que a torna neste caso, diferente dos adultos.

Encontramos ainda nos relatos as características de ser capaz de fazer opções, de ter idéias, gostos e opiniões próprias, e ainda de ser humano completo para a fase da vida na qual se encontra.

"Então não se deve impor a uma criança, alguma situação que ela não queira, antes de saber se é isso que ela realmente deseja" . (Segundo momento, Relato 03)

Decorre de todas essas características expostas, o entendimento de criança como cidadão, capaz e pronto a ocupar o seu espaço na vida em sociedade.

A Constituição de 1988 definiu, no artigo 227, os Direitos Constitucionais Brasileiros da Criança e do Adolescente e reconheceu, assim, sua cidadania social (BRASIL, 1988). Estes foram regulamentados pela Lei n. ${ }^{\circ} 8069 / 90$, o Estatuto da Criança e do Adolescente, que garante os direitos de toda criança, independentemente de sua raça, credo, nível social ou cultural.

Para que a criança seja tratada como cidadã impõe-se garantir o direito ao respeito, à vida, a um desenvolvimento harmonioso, além de supridas as necessidades materiais, físicas, orgânicas e afetivas. Para que o adulto consiga oferecer essas condições à criança, ele terá que mudar sua percepção em relação a ela.

Se partirmos do pressuposto de que a criança é um cidadão do presente, e como tal tem direitos e necessidades como todos os demais cidadãos, passaremos a permitir que tome parte de sua história e tenha garantidos seus direitos.

\subsection{Ser que se diverte}

A imagem da criança é associada, neste núcleo, à diversão, ou seja, em oposição ao adulto, à infância é preconizado o mundo do lazer e não o mundo do trabalho.

Associa-se à criança, elementos que compõem o mundo da diversão, como brinquedos, circo e parques. $\mathrm{O}$ trabalho é considerado precoce à essa fase da vida e está associado ao conceito de produtividade, portanto a criança é socialmente aceita como improdutiva.

"Ser criança é não ter preocupação com nada, é brincar, correr... (Primeiro momento, Relato 16)

"Tem que aprender a deixar as crianças serem crianças, sem preocupação, só divertimento". (Segundo momento, Relato 04) 
"Quando falamos em criança, logo pensamos em brinquedos, doces, parques, circos, pipoca, etc...todos os tipos de diversão..." (Primeiro momento, Relato 02)

Para KNOBEL (1992), o mundo da criança é o mundo dos brinquedos, através do qual ela elabora conflitos, aprende a adaptar-se à realidade e se prepara para atividades mais produtivas e construtivas que desempenhará mais tarde. Ainda para o autor são os jogos e brincadeiras que vão capacitar, progressivamente, a criança para as tarefas adultas, além de aperfeiçoar suas habilidades naturais, aumentando assim as perspectivas de trabalho.

Sabemos, como bem nos mostra a literatura, que a imagem de que o lazer e a brincadeira estão associados à infância nem sempre existiu. A brincadeira só veio a se tornar monopólio da infância na idade moderna, pois na antigüidade a criança dividia brinquedos e brincadeiras com o adulto (ARIÉS, 1981).

\subsection{O ambiente e a formação da criança}

O desenvolvimento da criança contempla a interação entre o biológico, o genético e o exterior, representado pelo ambiente material e humano. É a partir do equilíbrio entre esses elementos que o processo/ fenômeno acontece harmonicamente (MACHADO, 1985)

O ambiente sócio-econômico, onde a criança vive, é apontado neste núcleo, como fator determinante na sua formação, isto é, o adulto é produto do meio no qual a sua infância foi vivida.

Dentre os aspectos do ambiente, foi apontado o fator sócio-econômico como sendo um dos elementos desencadeadores da introdução precoce da criança na vida adulta, e também na vida nas ruas.

"... produto do meio, que existe diferenças entre uma criança nascida numa família de classe social mais favorecida, para uma da favela ou ainda outra abandonada nas ruas". (Primeiro momento, Relato 05)

As "Crianças de Rua", são as que não possuem um lar, vivem nas ruas, e não têm a oportunidade de desfrutar da fase na qual se encontram - a infância. Na realidade, tornam-se adultos muito cedo e contrariam as expectativas que estes haviam depositado para esta fase da vida.

“....vejo muitas crianças se drogando, se pendurando nos ônibus, perturbando pessoas...." (Primeiro momento, Relato 12)

Estas crianças adotam o modo de vida que lhes é imposto pelas condições sócio-econômica da família - passam a roubar, prostituir-se, drogar-se, cometer homicídios, sendo também nesse processo, maltratadas e marginalizadas.

"Cada vez mais cresce o número de crianças de rua, que deixam o seu lado infantil e passam a roubar, matar, se drogar, se prostituir, passando assim a se marginalizar perante a sociedade". (Primeiro momento, Relato 16)

Sabemos que as crianças de rua são introduzidas precocemente no mundo adulto e, para muitas delas estar na rua significa que, além da busca pela sobrevivência, lhe está sendo roubada a única forma que ela tem de expressar-se no mundo, o brincar.

As condições sócio-econômicas do ambiente, já abordadas, explicam, na percepção das alunas, a existência da "Criança de Rua".

"A situação econômica da família influencia diretamente na vida da criança. Por exemplo, se for uma família com renda muito baixa, a criança pode deixar os estudos, iniciar a trabalhar ainda muito pequena, viver nas ruas, ser abandonada, etc... Já uma criança de classe média, terá mais condições como: estudos, uma boa alimentação, tratamento médico, ou seja, terá outro padrão de vida". (Primeiro momento, Relato 01)

Dados do FIBGE (1992), apontam que mais de 25 milhões de crianças e adolescentes brasileiros vivem em situação de pobreza, em precárias condições de habitação, lazer, educação, saúde, alimentação, dentre outros, o que leva a pertencer a um grupo de extremo risco não só para doenças da miséria, como também para as várias modalidades de violência e agressão biológica, social, física, emocional e comportamental, em muitos casos, até no âmbito da própria família.

Outro aspecto do ambiente apontado foi aquele que diz respeito às relações familiares, que exercem grande influência na formação, educação, comportamento, personalidade e afetividade da criança. Este aspecto ficou particularmente forte por ocasião da segunda etapa de relatos.

"...pais e educadores têm um papel fundamental para seu desenvolvimento neuropsicomotor..." (Segundo momento, Relato 09)

"...mas que necessita de ajuda de um adulto para desenvolver-se e chegar a ser um adulto independente". (Segundo momento, Relato 01)

"O meio em que vive é essencial para sua formação e definição da personalidade. Necessita de orientação permanente..." 


\section{(Segundo momento, Relato 12)}

\subsection{Ser em fase de desenvolvimento}

Após a realização da disciplina, as alunas passaram a perceber a criança como ser em fase de desenvolvimento.

"Ela é um ser humano em desenvolvimento". (Segundo momento, Relato 10)

"Um ser que tem suas potencialidades e precisam ser desenvolvidas dentro de seus parâmetros e conforme sua idade". (Segundo momento, Relato 11)

"...tudo isso conforme a sua fase de desenvolvimento" . (Segundo momento, Relato 03)

"Ao adulto cabe ajudar a criança no que for preciso, para seu total desenvolvimento..." (Segundo momento, Relato 01)

Esta percepção foi evidenciada somente no segundo momento de relatos, o que poderia estar associado à experiência vivenciada no decorrer do estágio, e também em função das discussões encaminhadas durante a disciplina.

Considerando que a infância se caracteriza por uma sucessão de etapas do desenvolvimento, cada uma com suas peculiaridades, a criança requer algumas condições para favorecer o seu desenvolvimento; tais como: convívio familiar e social, nutrição, saúde, proteção, respeito, educação e brincar (VERISSÍMO \& SIGAUD, 1996). Cabe pois, aos pais, educadores, profissionais da saúde e à sociedade em geral proporcionar às crianças um desenvolvimento integral.

A curiosidade e a percepção infantil aguçadas são especialmente destacadas como aspectos característicos da infância, através das quais a criança constantemente aprende.

"Ser humano dotado de grande capacidade perceptiva e criativa". "...a busca do conhecimento despertado principalmente pela curiosidade". (Segundo momento, Relato 12)

\subsection{A interação da criança com o adulto}

Foi possível compreender que no processo interacional, a criança desperta uma série de sentimentos e comportamentos, com os quais o adulto passa a ter de lidar.

A criança é percebida como um ser que depende do adulto, por não ser capaz de realizar atividades sozinha. É colocada a perspectiva da criança tornar-se independente do adulto no futuro, não necessitando mais de auxílio.

"..precisam de auxílio para atividades corriqueiras, mas com o passar do tempo acabam conquistando a independência, pois não precisarão mais de ninguém para auxiliá-las". (Primeiro momento, Relato 13)

WINNICOTT (1996), ao discutir os cuidados infantis, coloca-nos que a dependência faz parte do desenvolvimento infantil. Para ele, a dependência possuí uma trajetória que vai de uma absoluta dependência a uma dependência relativa em direção à independência. Isso fica claro na fala acima.

A criança desperta vários sentimentos no adulto, no processo de interação que estabelece com ele. Os sentimentos variam de alegria, gratificação, carinho, até cansaço, perda de paciência e tensão nervosa.

"Passa a nos transmitir alegria, pois é gostoso e muito gratificante pegar um bebê no colo". (Primeiro momento, Relato 02)

As alegrias que a criança transmite ao adulto, são decorrentes da percepção de criança como ser "engraçado", "bonitinho", uma "coisa a ser admirada", "um objeto agradável". Além disso, as expectativas que o adulto deposita na criança são fontes de alegrias e gratificação.

"Como é gostoso receber um beijinho de uma criança, tão inocente, carinhoso e muito sincero". (Primeiro momento, Relato 10)

O sentimento de que a criança é fonte de distração e alegria para o adulto esteve presente desde o século XVI, podendo ser visto em pinturas e textos literários da época, denominado de "paparicação" (ARIÉS, 1981). Segundo o autor, este sentimento era reservado à criança em seus primeiros anos de vida, época em que era considerada "engraçadinha".

Por outro lado, para as alunas a criança é um ser que realiza atos considerados errados pelos adultos, "as artes", requerendo paciência para lidar com ela, e com os sentimentos que o seu comportamento desperta.

"...mas que também às vezes é capaz de nos atormentar com certas travessuras que só elas sabem fazer". (Primeiro momento, Relato 08)

"Eu gosto muito de crianças, mas às vezes me falta paciência para lidar com elas..." (Segundo momento, Relato 08) "...porque antes eu gostava de dar umas palmadas (em minha filha)". (Segundo momento, Relato 08)

Para SANTANA (1995) não é incomum adultos 
perderem a paciência com crianças em decorrência de algum comportamento desta. Isto ocorre em virtude de não entenderem que determinadas características apresentadas por elas são próprias da idade. Para a autora, muitas das dificuldades no trato com a criança são geradas pelo desconhecimento de sua natureza.

No segundo momento de relatos, aparecem os significados já apresentados, e ainda a necessidade do adulto preparar-se para cuidar de crianças.

"...vejo que existe uma grande necessidade de melhoramento não só da educação delas próprias, mas sim das pessoas que estão convivendo junto a seu meio ". (Segundo momento, Relato 09)

Fica evidente ainda, que o adulto percebe a criança como um ser através do qual, tem a possibilidade de realizar desejos e projetos de vida pessoais, que não tenha conseguido levar a cabo. Na verdade, o adulto projeta-se na criança, através daquilo que ela irá realizar por ele, no futuro (BETTS, 1994).

“...também são vítimas dos adultos que fazem delas bonecos e planejam toda sua vida do jeito que eles queriam que fosse a deles". (Segundo momento, Relato 04)

DALLARI \& KORCZAC (1986) colocam que a percepção de criança comum em nosso meio cultural é de seres que se deixam guiar por impulsos, que vivem em um mundo de fantasias, apresentam uma estrutura psíquica não diferente do adulto, mas sim inferior. Em decorrência da comparação que se faz com as características do adulto, acabamos por concluir que as crianças são inferiores a eles.

Essa percepção culturalmente preservada do ser criança leva os adultos a se sentirem no direito e com poderes suficientes para moldá-la de acordo com as crenças, valores e padrões estabelecidos pela sociedade, afim de que possam realizar os projetos e sonhos idealizados por seus responsáveis.

\section{5 - CONSIDERAÇÕES FINAIS}

Percebe-se, no decorrer do trabalho com as alunas, momentos de contradições, idas e voltas acerca da percepção de criança.

Inicialmente as alunas percebem a criança como um ser frágil, imaturo, portanto despreparados para enfrentar a vida, necessitando da proteção do adulto.

Comparando as percepções do início e após o término da disciplina, as alunas passam a ver a criança como um ser em fase de desenvolvimento, considerandoas como cidadãos, ou seja, com os mesmos direitos do adulto.

Este trabalho permitiu verificar que a visão de crianças incorporada pelas alunas guarda uma importância vital no momento em que as mesmas vão efetivar sua assistência à criança. Aprofundar esta questão e a partir daí viabilizar mudanças no processo ensino-aprendizagem junto à criança, é um novo desafio, que seguramente refletirá na prática profissional daqueles atores que interagem no dia-a-dia com a criança.

Ressaltamos, pois, a necessidade de que esta questão seja cada vez mais discutida, tanto no processo assistencial como de ensino-aprendizagem, caracterizando uma condição indispensável à consolidação de uma efetiva transformação no cuidar e perceber a criança como ser cidadão.

\section{PERCEPTION OF CHILDREN BY NURSING UNDERGRADUATE STUDENTS}

The purpose of the present study was to determine the perception of children by nursing undergraduate students in a Brazilian Public University. The students were asked to write about their perception of children on the first and last day of their academic activities in pediatric nursing. Using a qualitative approach, the authors analyzed the reports and identified the following thematic nuclei: "a small, fragile and innocent being", "citizen human being", "human being in the developmental phase", "a being who has fun", "the environment and child training", and "interaction of children with adults". Results show that at first the students perceived children as fragile, immature beings unprepared to face life and needing adult protection. At the end of the course, they started to see children as developing beings and as citizens with the same rights as adults.

KEY WORDS: perception of children, nursing students

\section{EL SER NIÑO: PERCEPCIÓN DE ALUMNAS DE UN CURSO DE PREGRADO DE ENFERMERÍA}

Las autoras tuvieron como objetivo conocer la percepción sobre el ser niño, que tienen las alumnas del cuarto semestre de pregrado en enfermería de una Universidad Pública Brasileña. Para esto solicitaron a las alumnas que escribieran acerca de su percepción sobre el niño, en el primero y último día de actividades académicas de la disciplina de enfermería pediatrica. 
Utilizando un abordaje cualitativo, analizaron los relatos, identificando los siguientes núcleos temáticos: "ser pequeño, frágil e inocente", "ser humano ciudadano", "ser humano en fase de desarrollo", "ser que se divierte", "El ambiente y la formación del niño" y la "interacción del niño con el adulto". Los resultados muestran que inicialmente las alumnas percibían al niño como ser frágil, inmaduro y no preparado para enfrentar la vida, necesitando de la protección del adulto. Al final de la disciplina pasan a ver al niño, como un ser en fase de desarollo, como ciudadano y con los mismos derechos del adulto.

TÉRMINOS CLAVES: percepción del niño, alumnas de enfermería

\section{6 - REFERÊNCIAS BIBLIOGRÁFICAS}

01. ÂNGELO, M. Saúde da criança e do adolescente. Políticas e saúde: aspectos técnicos, científicos e éticos, s.d.( mimeografado).

02. ARIÉS, P. História social da criança e da família. 2.ed. Rio de Janeiro: Zahar, 1981.

03. BADINTER, E. Um amor conquistado: o mito do amor materno. 8 ed. Rio de Janeiro: Nova Fronteira, 1985.

04. BETTS, J.A. Missão impossível?: sexo, educação e ficção científica. In: CALLIGARIS, C. et al. Educa-se uma criança? Porto Alegre: Artes e Ofícios, 1994, p. 47-62.

05. BRASIL. Constituição: República Federativa do Brasil, 1988. Brasília: Senado Federal, Centro Gráfico, 1988.

06. BRASIL. Ministério da Saúde. Estatuto da criança e do adolescente. Brasília: Ministério da Saúde, 1991.

07. COVRE-MANZINI, M. de L. O que é cidadania. 3. ed. São Paulo: Brasiliense, 1995. (Coleção Primeiros Passos)

08. DALLARI, D.A.; KORCZAC, J. O direito da criança ao respeito. 2. ed. São Paulo: Summus, 1986.

09. FERREIRA, A.B. de H. Novo dicionário Aurélio de língua portuguesa. Rio de Janeiro: Nova Fronteira, 1986.
10. FUNDAÇÃO INSTITUTO BRASILEIRO DE GEOGRAFIA E ESTATÍSTICA-IBGE. Crianças e adolescentes: indicadores sociais. Rio de Janeiro, 1992.v. 4.

11. KNOBEL, M. Orientação familiar. Campinas: Papirus, 1992.

12. LÜDKE, M.; ANDRÉ, M.E.D. Pesquisa em educação: abordagens qualitativas. São Paulo: EPU, 1986.

13. MACHADO, D.V.M. Higiene mental. In: MARCONDES, E. Pediatria básica. 7. ed. São Paulo: Sarvier, 1985. $2^{\mathrm{a}}$ parte, p. 119-125.

14. SANTANA, J. S. S. O significado da experiência de creche expresso pela criança. Salvador, 1995. 175p. Dissertação (Mestrado)-Universidade Federal da Bahia.

15. TRIVIÑOS, A.N.S. Introdução à pesquisa em ciências sociais: a pesquisa qualitativa em educação. São Paulo: Atlas, 1987.

16. VERÍSSIMO, M.D.O.R.; SIGAUD, C.H.S. Enfermagem pediátrica: o cuidado de enfermagem à criança e ao adolescente. São Paulo: EPU, 1996.

17. WHALEY, L.F.; WONG, D.L. Enfermagem pediátrica: elementos essenciais à integração efetiva (Essentials of pediatric nursing). 2. ed. Rio de Janeiro: Guanabara Koogan, 1989.

18. WINNICOTT, D.W. Os bebês e suas mães. 2 ed. São Paulo: Martins Fontes, 1994. 